\title{
Experiences and Trends in Control Education: A HiOA/USN Perspective
}

\author{
Tiina M. Komulainen $^{1} \quad$ Alex Alcocer $^{1} \quad$ Finn Aakre Haugen ${ }^{2}$ \\ ${ }^{1}$ Department of Electronics Engineering, Oslo and Akershus University College of Applied Sciences (HiOA), Oslo, \\ Norway, tiina.komulainen@hioa.no, alex.alcocer@hioa.no \\ ${ }^{2}$ Institute of Electrical Engineering, Information Technology and Cybernetics, University College of Southeast \\ Norway (USN), Porsgrunn, Norway, finn.haugen@usn.no
}

\begin{abstract}
Global trends in higher education including e-learning, massive open online courses, and new teaching methods have positively affected control education. Control course content has evolved due to changes in industrial practices and the increasing availability of affordable computer hardware and software. Continuous developments in virtual remote and real laboratories have made hands-on tasks more accessible and affordable. In this article, we share our experiences of undergraduate and graduate control education at the University College of Southeast Norway (USN), and Oslo and Akershus University College of Applied Sciences (HiOA). First, we present an overview of the course content at our institutions, and then, we give examples of the development of real and virtual laboratories, online course materials, new learning platforms, and teaching methods.
\end{abstract}

Keywords: control education, control laboratories, virtual laboratories, simulation, learning management systems, active learning methods

\section{Educational trends}

\subsection{Trends in higher education}

Massive open online courses (MOOCs), e-learning, electronic learning management systems, and student active learning methods have become major trends in higher education in Science, Technology, Engineering, and Mathematics (STEM).

During the past decade, the variety of massive open online courses (MOOC) has expanded and many top universities are offering a wide spectrum of courses (Hansen and Reich, 2015). MOOCs combine teaching from the best academics, modern pedagogy, interactive content, virtual laboratories, and online group discussions delivered through non-profit platforms such as edX, Coursera, and Udacity (Waldrop, 2013). However, the academic content should be supplemented with hands-on experiments supervised by experienced teachers in order to build practical skills (Bartholet, 2013).

For on-campus STEM education, student active learning methods have been proven to increase students' learning outcomes and to decrease drop-out rates (Fraser et al., 2014; Freeman et al., 2014; Hake, 1998). Examples of the successful implementation of student active learning methods in groups in technology-rich rooms are SCALE-UP (Student-Centered Active Learning Environment for Undergraduate Programs) at North Carolina State University (Beichner et al., 2007) and TEAL (Technology-Enabled Active Learning) at the Massachusetts Institute of Technology (Dori and Belcher, 2005). The pedagogy is typically based on Flipped Classroom (FC) methodology, where students are required to have their first exposure to the subject material at home prior to class, and where class time is spent working with the material (Bergmann and Sams, 2012).

\subsection{Trends in teaching aids for control education}

Based on the 62 papers presented at the 10th IFAC Symposium on Advances in Control Education (Rossiter, 2013), course development is most active in the following topics: remote laboratories $(21 \%)$, real laboratories (19\%), teaching aids (19\%), virtual laboratories (11\%), e-learning (11\%), robotics $(10 \%)$, and course content $(8 \%)$. Many educators aim to make part of the resource and time demanding real laboratories more easily accessible through the internet. However, real laboratories are needed in order to ensure practical hands-on skills for the students.

\subsection{Trends in the content of control education}

Taking well-known text-books, e.g. (Dorf and Bishop, 2016; Franklin et al., 2014; Nise, 2015; Seborg et al., 2011), as indicators of the course content, it seems that the theoretical content of control courses has not changed much over the last decades. Differential equations, transfer functions, state-space models, and frequency response - in the continuous-time and in the 
discrete-time domain, comprise the basis, as they did decades ago. Mathworks MATLAB seems to be the default computing tool upon which exercises in textbooks are based, but National Instruments MathScript and LabVIEW are also used as tools.

We find it somewhat surprising to observe that most textbooks apparently aiming to present a good basis for control theory, do not include model-based predictive control (MPC), with (Seborg et al., 2011) as the exception, despite the fact that MPC theory and applications are frequent topics in journals and conferences, as well as there being many commercial software packages for MPC. One reason for the lack of focus on MPC may be that its theoretical basis is optimization theory - a topic not usually taught at undergraduate level.

\section{Control education at HiOA and USN}

In this article, we share our experiences of undergraduate and graduate control education at the University College of Southeast Norway (USN), and Oslo and Akershus University College of Applied Sciences (HiOA). First, we present an overview of the course content at our institutions, and then, we give examples of the development of real and virtual laboratories, online course materials, new learning platforms, and teaching methods.

\subsection{Control education at USN/Porsgrunn}

Subsections are numbered and style "Heading 2" should be used.

The University of Southeast Norway (USN) has approximately 16,000 students. Control is taught in various courses at three different campuses. The courses covered here are introductory courses in the bachelor and master programs at the Porsgrunn campus.

The control courses have developed over the years. The main driving forces behind the developments are:

- A desire to increase the students' ability to handle practical control challenges. This requires developing both the pedagogics and the content of the courses.

- Feedback from students, in particular from those who have industrial experience in automation and control.

- Teachers' experience in research and development, in particular the relationship between theory and practice.

- Technological changes entailing increasing availability of affordable computer hardware and software.

In the following, firstly the development of course content is described, and secondly, pedagogical development is described.

\section{Content development}

Highlights of the content development are:

- Only experimental PID controller tuning methods are presented, both open loop tuning and closed loop tuning, are taught. Open loop tuning focuses on a process of step-response interpretation of the Skogestad PI tuning rules assuming integrator + transport delay process dynamics (Skogestad, 2003), but also tuning double integrator process dynamics is covered (the double integrator can represent bodies to be position controlled, e.g. ships). Closed loop tuning focuses on the ZieglerNichols Ultimate Gain method, both the original tuning rules (Ziegler and Nichols, 1942) and modified tuning rules. Frequency response based tuning methods are not covered.

- Feedforward control with possibly nonlinear differential equation models where the feedforward controller is obtained by substituting the process output variable by its set point and then solving the model for the control variable.

- The Laplace transform, transfer functions, and frequency response analysis are very briefly covered. Down-toning frequency response is in agreement with the low priority given to this topic as indicated by the industrial perspective in the reports (Edgar et al., 2006) and (Haugen, 2009).

- Leaving out theoretical stability analysis in the frequency domain. However, the gain margin and phase margin of control loops are introduced using an experimental loop stability analysis approach (Haugen, 2012).

- Discrete-time algorithms of the PID controller, a time-constant measurement filter, and process simulators.

- Principles and applications of model-based predictive control (MPC) are introduced as the most important model-based controller.

- In one of the introductory courses, an industrial process and control system simulator is introduced (the Kongsberg Oil \& Gas Technologies K-Spice simulator).

- Programming skills, making the students able to actually implement control, filter, and simulation algorithms. To this end, National Instruments LabVIEW is introduced as the programming tool.

\section{Pedagogical development}

Highlights of the pedagogical developments are:

- Interactive real-time simulators from the SimView library (Haugen, 2012) are used extensively in the theoretical exercises.

- Instructional videos supplementing the lectures (Haugen, 2011). 
- During 2016 and 2017, two introductory control courses will be offered both as online courses and traditional campus-based courses. Instructional videos will substitute traditional lectures in the online courses. However, laboratory exercises will, to the extent practical, still be a part of the course, requiring the online students to come to the campus to carry out the experimental work over two or three days.

- A relatively large number of laboratory exercises based on the air heater (Figure 1) are closely integrated with the lectures.

\subsection{Control education at HiOA/Oslo}

HiOA has approximately 18,000 students, 1,900 study engineering and 310 are undergraduate students in electronics engineering. At the undergraduate level HiOA offers courses in Dynamic Systems, Control Systems I, Control Systems II and Instrumentation. The courses cover the following topics:

Dynamic Systems: Basic introductory course on mathematical modeling and dynamic systems analysis. Differential equations, transfer functions, block diagrams, state-space models, frequency analysis, and time response.

Control Systems I: Basic introductory course on control. PID regulator, process simulation, frequency domain control design, Introduction to multivariable control.

Control Systems II: More advanced topics in control. Noise filtering, System identification, Kalman filtering, LQR/LQG control, MPC control. Introduction to nonlinear control.

Instrumentation: Instrumentation for control system engineers, sensor and actuator specifications, instrumentation diagrams, regulations and safety, PLC architecture and PLC programming.

Industrial hardware and software such as ABB's 800xA control system and Kongsberg's K-Spice simulator, are used in the laboratories for all our control courses.

\subsection{Accessible Laboratory Exercises}

At USN, a number of laboratory exercises are based on the air heater (Haugen, 2010) shown in Figure 1. Together with LabVIEW on students' laptops and the NI USB-6008 IO device, laboratory exercises are run throughout the course, with students working in groups of two or three, see Figure 2. Twenty-six identical rigs have been constructed in-house.
2. Implementation of a dynamic process simulator from a time-constant and time-delay model with default model parameter values.

3. Adaptation of the mathematical model, i.e. parameter estimation, using a straightforward, "brute force" least squares method implemented in nested for-loops.

4. Implementation of a discrete-time PI controller and an on/off controller.

5. Implementation of a discrete-time time-constant lowpass filter.

6. Controller tuning using Skogestad's tuning rules and the Ziegler-Nichols Ultimate Gain method, see above.

7. The stability of the control loop. Hitherto, a qualitative analysis is included, including the stability impact of controller gain (both absolute value and sign), integral time, and filter timeconstant. In the future, an experimental estimation of gain margin and phase margin [20] will be included.

8. Experimental, table-lookup feedforward control with air flow (disturbance) measurement as input signal and heater control signal as output signal.

9. Temperature control with an industrial PID controller (Fuji PGX5), instead of the LabVIEWbased control system.

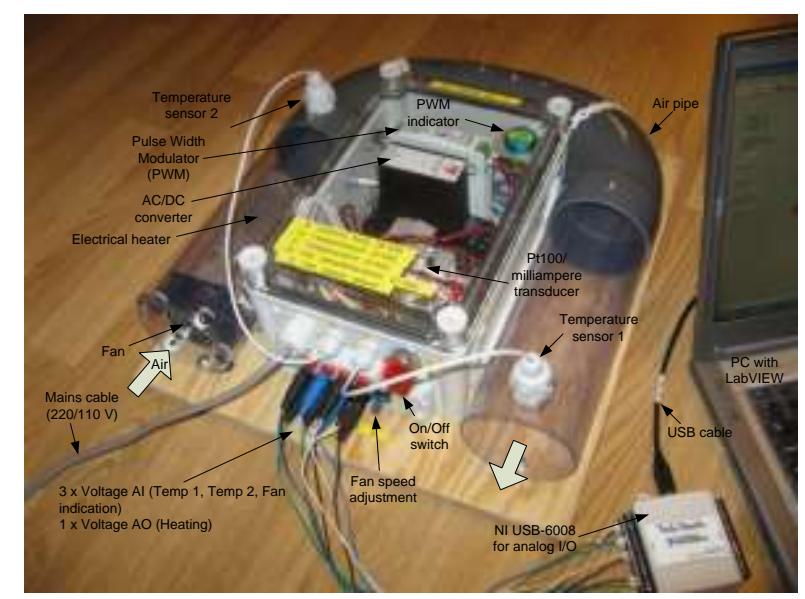

Figure 1: Air heater laboratory rig for temperature control. The voltage control signal manipulates the power delivered by the electrical heater. The outlet temperature is measured by a Pt100 element. The air flow through the pipe can be manually adjusted, representing a (measured) process disturbance.

The laboratory assignments cover:

1. Manual temperature control, monitoring, and data logging to file. 


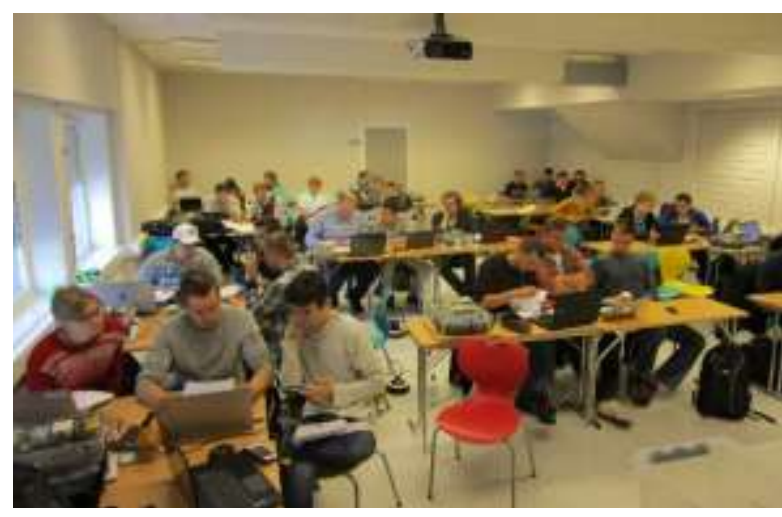

Figure 2: Students working on laboratory assignments in groups.

\subsection{Virtual laboratories / Commercial Large- Scale Simulators}

In order to familiarize our students with industrial tools, and to give them insight into chemical processes, commercial large-scale dynamic process simulators have been utilized at HiOA (Komulainen and Løvmo, 2014; Komulainen, 2013; Komulainen et al., 2012). The simulation modules have been developed using the didactic model and the simulator training structure: briefing (lecture) - simulation (guided virtual laboratory) - debriefing (workshop). The simulation software K-Spice is provided by Kongsberg Oil and Gas Technologies Figure 3.

In the following, an example is given of the Dynamic Systems course which is taught to about 60 second year undergraduate electronics engineering students. Two of the learning outcomes of the course are "Student can characterize responses of first and second order systems in time and frequency domain" and "Student can carry out simulation of dynamic systems and interpret the results". The goal of the simulation module is to give the students hands-on skills to use an industrial simulator, to make a step change and identify the process response. The parameters of the process response will be used further for control tuning purposes.

The experiences from the simulator module are positive, the students and the teacher were very positive in their evaluation, $97 \%$ of students agreed that simulation exercises increase their understanding of process dynamics. However, the final exam results for the identification tasks were lower than the average final exam mark for both 2013 and and 2014 (Komulainen and Løvmo, 2014). In order to enhance learning through simulation training, we are currently working on developing an automatic assessment system (Marcano and Komulainen, 2016).

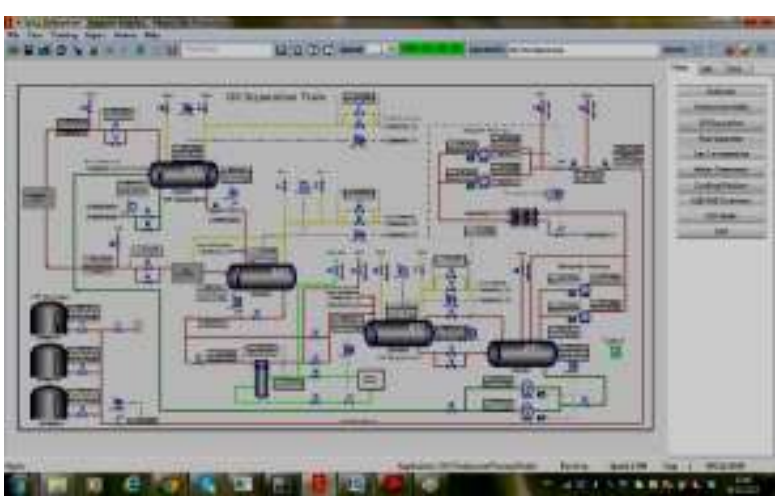

Figure 3: K-Spice ${ }^{\circledR}$ generic oil and gas production simulator.

\subsection{Jupyter notebooks and interactive code}

Numerical simulation tools have a crucial role in increasing the understanding of control theoretical concepts as well as providing insight and promoting the curiosity and engagement of students (Dormido et al., 2005; Grega, 1999). Typically, MATLAB/Simulink is the numerical simulation software tool of choice in most current control systems courses. Alternatives exist that are gradually providing similar functionalities, which are also open source and free. These include GNU Octave (Eaton, 2016) and Python.

Automatic control is a highly multidisciplinary subject, which has been referred to as the "hidden technology"(Åström, 1999). It involves, among others, the fields of mathematics, physics, electrical and mechanical engineering. In practice, all modern control systems are eventually implemented using some sort of software and programming language. Software development is therefore becoming an increasingly important and required skill, and its importance has naturally gradually increased in control engineering course curriculums (Bencomo, 2004; Åström and Kumar, 2014).

A relatively recent technology enables interactive code to be integrated with rich text in so-called notebooks (Shen, 2014). Notebooks can be viewed and executed using a simple internet browser. This provides an excellent way of distributing educational content and providing students with an initial executable code with which to experiment and develop new ideas. Jupyter is at the forefront of this technology and provides support for a great number of programming languages including Julia, Python, and R (Project Jupyter, 2016). Notebooks can be viewed in an internet browser using a notebook viewer (nbviewer) which does not require any special software. Additionally, the students can chose to download the notebooks to their computers where they have the possibility to interact and modify the initial code.

Python is a popular object-oriented scientific programming language that is becoming increasingly used in research and industry. Several Python libraries exist that are of interest to control engineering students. 
For instance numpy and matplotlib provide numerical and data visualization tools that are quite similar to MATLAB. The python control systems library (Murray and Livingston, 2009) is particularly interesting. It implements basic operations for analysis and design of feedback control systems including block diagram algebra, Bode and Nyquist plots, time response, etc. By installing a Python scientific distribution, such as continuum analytics anaconda, the student can easily experiment with these open source tools at no cost. An example of notebook using python, numpy, and matplotlib to easily visualize simulation results (Alcocer, 2016).

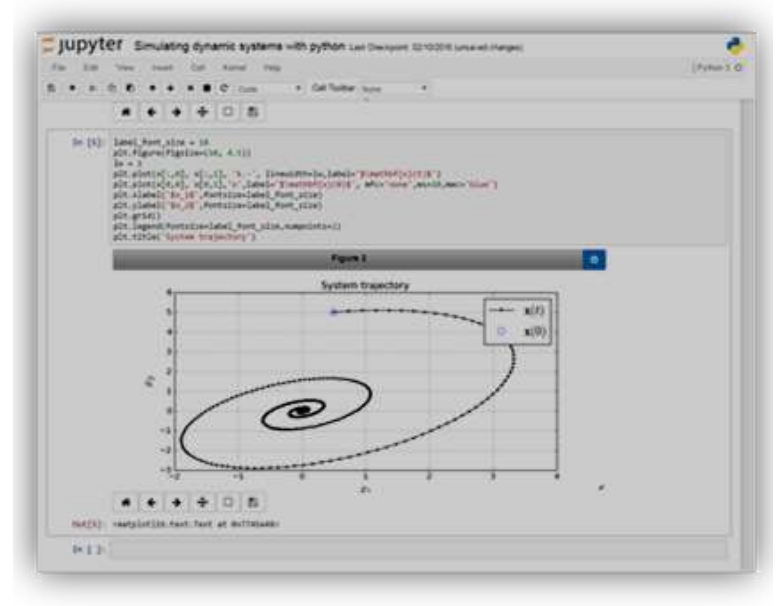

Figure 4: Example of interactive code using a browser, Jupyter notebook, and Python-Control toolbox.

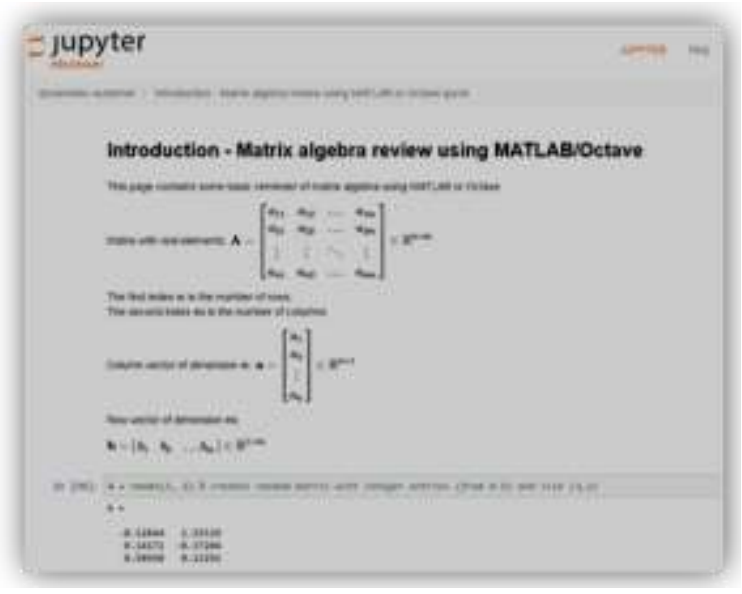

Figure 5: Example of Jupyter notebook using an Octave kernel.

Another interesting possibility is the use of Octave kernel together with Jupyter notebooks. GNU Octave is an open source scientific programming language with a syntax very similar to MATLAB. This provides the possibility of distributing educational notebooks with text, mathematical equations, and code. See Figure 5 for an example of a Jupyter notebook using Octave.

\subsection{Learning Management Systems and OpenEdx}

OpenEdx is currently one of the most popular open source MOOC platforms. The introductory undergraduate dynamic systems course at HiOA is going to experiment with the use of OpenEdx, see Figure 6. One of the most appealing functionalities is its ability to provide quizzes for the students for each of the units, which provides feedback on and interactivity with the learning experience. With OpenEdx, it is simple to include LaTeX style mathematical expressions integrated in quizzes, which provides a great level of flexibility.

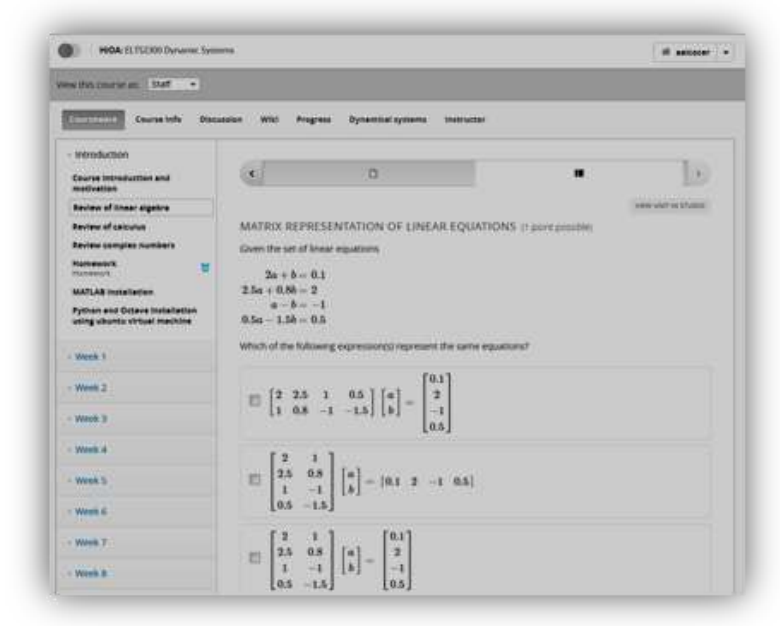

Figure 6: Example of OpenEdx course with quizzes containing mathematical expressions.

\subsection{Student Active Learning Methods}

At HiOA we have tested Flipped Classroom inspired teaching methods in a technology-rich group room (Komulainen et al., 2015). The experiment was conducted in a dynamic systems course with about 60 students during fall semester 2014. The main goal of the research was to find out if students' learning outcome would increase as a result of the use of student active learning methods. The data collection included students' course evaluation, students' attendance, students' pre and post scores from the Control Systems Concept Inventory (Bristow et al., 2012), teachers' classroomactivity $\log$, five in-class mini-tests, and final exam grades.

The students were given reading assignments with theory quizzes prior to the classroom sessions. During the classes, the students worked in small groups of three to four students and used a small screen at the end of each table to present the work of their group. Short tasks (5-20 min) were given on concepts, theory and basic calculations, long exercises (20-45 $\mathrm{min}$ ) on modeling of dynamic systems and simulation of these models with Matlab/Simulink. After each task, the teacher chose one of the groups to present its results to the whole class. 
These plenary presentations were facilitated with large screens using AirMedia software. Every other week, the students took a 20-minute mini-test on theory and modeling. The mini-test was graded by the peer students immediately afterwards based on the solution presented by the teacher on the SmartBoard.

The students' course evaluation indicated that $70 \%$ of the students preferred the active learning classroom to traditional lecturing. Students valued the mini-tests as a tool to monitor their own progress in the course and they emphasized the good learning outcome of the group work. The students gave the course a final average mark of B.

Student attendance of $72 \%$ was considered good and above average for this student cohort. However, only $42 \%$ of the students answered the quizzes prior to the classes. Students' conceptual understanding increased during the course, the normalized gain was $20 \%$ measured by the Control Systems Concept Inventory. The average final grade for the course in dynamic systems was compared to the average final grade for the course in electrical circuits between cohort 2013 (traditional lecturing) and cohort 2014 (active learning methods). The average grade in electric circuits was 3.94 for cohort 2013 and 3.35 for cohort 2014, indicating that cohort 2013 was academically stronger than cohort 2014. However, the difference between the cohorts had become non-significant after the dynamic systems course; the final grade was 2.64 for cohort 2013 and 2.63 for cohort 2014. Although the results were not conclusive, the results indicate that active learning methods applied in 2014 were more valuable to student learning than traditional lecturing.

\section{Discussion and conclusions}

Global trends in higher education, online course materials and affordable hardware and software have provided great possibilities for making control education more accessible, efficient, and interesting to students, teachers and universities. In this article we have provided examples of experiences at USN and HiOA, and have shown how some of these teaching tools have been applied in control systems courses. Special attention is given to an experiment involving Flipped Classrom methodology together with a technology-rich group room. This teaching methodology was tested with positive results during an undergraduate dynamic systems course. The paper also discusses, among other things, the use of accessible laboratories, industrially relevant virtual laboratories, open source simulation tools, open learning management systems, and new teaching methods that are promising or have been successfully implemented in control systems courses at USN and HiOA.

\section{References}

A. Alcocer. Dynamiske-systemer. Available via https://github.com/aalcocer/dynamiske-systemer [accessed 18.05.2016, 2016].

J. Bartholet. MOOCs- Hype and Hope. Scientific American 309:53-61, 2013.

10.1038/scientificamerican0813-53

R. J. Beichner, J. M. Saul, D. S. Abbott, J. J. Morse, D. L. Deardorff et al., The Student-Centered Activities for Large Enrollment Undergraduate Programs (SCALEUP) Project, vol. 1, Research-Based Reform of University Physics, E. F. Redish and P. J. Cooney, Eds., College Park: American Association of Physics Teachers, 2007. [Online]. Available: http://www.compadre.org/per/per reviews/volume1. cfm. Accessed on 01.02.2015.

S. D. Bencomo. Control learning: present and future. Annual Reviews in control, 28(1):115-136, 2004.

J. Bergmann and A. Sams. In Flip Your Classroom: Reach Every Student in Every Class Every Day. International Society for Technology in Education, 2012.

M. Bristow, K. Erkorkmaz, J. P. Huissoon, S. Jeon, W. S. Owen, S. L. Waslander, and G. D. Stubley. A Control Systems Concept Inventory Test Design and Assessment. IEEE Transactions on Education, 55(2):10, 2012. doi: 10.1109/ TE.2011.2160946

R. Dorf and R. H. Bishop. In Modern Control Systems. 12 ed. Pearson, 2016.

Y. J. Dori and J. Belcher. How Does Technology-Enabled Active Learning Affect Undergraduate Students' Understanding of Electromagnetism Concepts? The journal of the learning sciences, 14(2):243-279, 2005.

S. Dormido, S. Dormido-Canto, R. Dormido, J. Sánchez, and N. Duro. The role of interactivity in control learning. International Journal of Engineering Education, 21(6):11-22, 2005.

J. W. Eaton. GNU Octave. Available via https://www.gnu.org/software/octave/ [accessed 18.05.2016, 2016].

T. F. Edgar, B. A. Ogunnaike, J. J. Downs, K. R. Muske, and B. W. Bequettee. Renovating the undergraduate process control course. Computers \& Chemical Engineering, 30:1749-1762, 2006.

G. Franklin, J. Powell, and A. Emami-Naeini. In A. Feedback Control of Dynamic Systems. 7 ed. Pearson, 2014.

J. M. Fraser, A. L. Timan, K. Miller, J. E. Dowd, L. Tucker, and E. Mazur. Teaching and physics education research: bridging the gap. Reports on Progress in Physics, 77(3):17, 2014. doi: 10.1088/00344885/77/3/032401

S. Freeman, S. L. Eddy, M. McDonough, M. K. Smith, N. Okoroafor, H. Jordt, and M.P. Wenderoth, Active learning increases student performance in science, engineering, and mathematics, Proceedings of the National Academy of 
Sciences of the United States of America (PNAS), p. 6, 15.04.2014. doi: 10.1073/pnas.1319030111

W. Grega. In Hardware-in-the-loop simulation and its application in control education. Frontiers in Education, San Juan, Puerto Rico 1999, volume 2, pages $12 \mathrm{~B} 6-7$.

R. R. Hake. Interactive-engagement versus traditional methods: A six-thousand-student survey of mechanics test data for introductory physics courses. American Journal of Physics, 66:64-74, 1998. doi: http://dx.doi.org/10.1119/1.18809

J. D. Hansen and J. Reich. Democratizing education? Examining access and usage patterns in massive open online courses. Science, 350(6265):1245-1248, 2015. doi: $10.1126 /$ science.aab3782

F. A. Haugen. (2009) Industrifolks syn på automatiseringsutdanningen (in English: Industrial perspective on control education). AMNytt. Available: http://techteach.no/publications/amnytt/web

F. A. Haugen. Lab Station: Air Heater. Available via http://home.hit.no/"finnh/air_heater [accessed 18.05.2016, 2010].

F. A. Haugen. TechVids. Available via http://techteach.no/techvids [accessed 18.05.2016, 2011].

F. A. Haugen. The Good Gain method for simple experimental tuning of PI controllers. Modeling, Identification, and Control, 33(4):141-152, 2012. doi: 10.4173/mic.2012.4.3

F. A. Haugen. SimView. Available via http://techteach.no/simview [accessed 18.05.2016, 2012].

T. Komulainen and T. Løvmo. In Large-Scale Training Simulators for Industry and Academia. 55th Conference on Simulation and Modelling, Aalborg, Denmark, 2014, volume 128-137.

T. M. Komulainen. In Integrating commercial process simulators into engineering courses. In A. Rossiter, editor, 10th IFAC Symposium Advances in Control Education, University of Sheffield, 2013, volume 10, pages 274-279 Sheffield, 2013. doi: 10.3182/20130828-3-UK-2039.00007

T. M. Komulainen, C. Lindstrøm, and T. A. Sandtrø. Erfaringer med studentaktive læringsformer i teknologirikt undervisningsrom. (in Norwegian), Uniped, 8(04):364-372, 2015.

T. M. Komulainen, R. Enemark-Rasmussen, G. Sin, J. P. Fletcher, and D. Cameron. Experiences on dynamic simulation software in chemical engineering education. Education for Chemical Engineers, 7(4):e153-e162, 2012. doi: 10.1016/j.ece.2012.07.003

L. A. Marcano and T. M. Komulainen. Constructive Assessment Method for Simulator Training. In Proceedings of the 9th Eurosim Congress on Modelling and Simulation, Oulu, Linköping University Press, 2016.
R. Murray and S. C. Livingston. Control Systems Library for Python. Available via https://github.com/pythoncontrol/ [accessed 18.05.2016, 2009].

N. S. Nise. In Control Systems Engineering. 7 ed. Wiley, 2015.

Project Jupyter. Jupyter. Available via http://jupyter.org/ [accessed 18.05.2016, 2016].

A. Rossiter. In Proceedings of the 10th IFAC Symposium Advances in Control Education. In Proceedings of 10th IFAC Symposium Advances in Control Education, Sheffield, Great Britain, 2013, volume 10. doi: 10.3182/20130828-3-UK-2039.00007

D. E. Seborg, D. A. Mellichamp, T. F. Edgar, and F. J. D. III. In Process dynamics and control. international student version 3 ed. Wiley, p. 528, 2011.

H. Shen. Nature toolbox: Interactive notebooks: Sharing the code. Nature, 515:151-152, 2014. doi: $10.1038 / 515151 \mathrm{a}$

S. Skogestad. Simple Analytical Rules for Model Reduction and PID Controller Tuning. Journal of Process Control, 13:291-309, 2003.

M. M. Waldrop. Education online: The virtual lab. Nature, 499:268-270, 2013. doi: 10.1038/499268a

J. G. Ziegler and N. B. Nichols. Optimum Settings for Automatic Controllers. ASME, 64:759-768, 1942.

K. J. Åström. Automatic control: The hidden technology. In P. M. Frank, editor, Advances in control: Highlights of ECC'99 pages 1-28: Springer Verlag, 1999

K. J. Åström and P. R. Kumar. Control: A perspective. Automatica, 50(1):3-43, 2014. 